\title{
Declaration of Helsinki
}

National Cancer Institute

\section{Source}

National Cancer Institute. Declaration of Helsinki. NCI Thesaurus. Code C142505.

A guiding statement, created by the World Medical Association (WMA) in Helsinki, Finland in 1964, that details a set of ethical principles for physicians and other participants in medical research. It has undergone a number of revisions over the years. 